\title{
Urgences
}

\section{La peur du noir}

\section{Hélène Tremblay}

Numéro 5, 3e trimestre 1982

URI : https://id.erudit.org/iderudit/025074ar

DOI : https://doi.org/10.7202/025074ar

Aller au sommaire du numéro

Éditeur(s)

Urgences

ISSN

0226-9554 (imprimé)

1927-3924 (numérique)

Découvrir la revue

Citer ce document

Tremblay, H. (1982). La peur du noir. Urgences, (5), 31-38.

https://doi.org/10.7202/025074ar

Ce document est protégé par la loi sur le droit d'auteur. L'utilisation des services d'Érudit (y compris la reproduction) est assujettie à sa politique d'utilisation que vous pouvez consulter en ligne.

https://apropos.erudit.org/fr/usagers/politique-dutilisation/
Cet article est diffusé et préservé par Érudit.

Érudit est un consortium interuniversitaire sans but lucratif composé de l'Université de Montréal, l'Université Laval et l'Université du Québec à Montréal. Il a pour mission la promotion et la valorisation de la recherche. https://www.erudit.org/fr/ 


\section{HÉLÈNE TREMBLAY}

\section{La peur du noir}

"Nul ne fait, en s'exprimant, mieux que s'accommoder à une possibilité de conciliation très obscure de ce qu'il savait avoir à dire avec ce que, sur le même sujet, il ne savait pas avoir d dire et que cependant il a dit". 


\title{
LES MASQUES
}

(à renard de LAPIN XXX)

\author{
é renard \\ toi qui poursuis le LAPIN en pleine névrose \\ traque-le jusqu'à cette maison \\ verte pas mûre \\ aux volets \\ rouges sang de boeuf \\ tu sais, celle sous les saules \\ sans larmes \\ bal fini ballon crevé \\ et ta ruse renard \\ perdue hi hi perdue hi hi hi \\ I'hystérie te guette \\ entre les pattes de la table \\ un lion t'attend \\ un lion aux yeux rouges sang de lapin
}




\section{CONTINE}

mon pitou à courte mémoire t'as mis souvenir dans le formol

y est donc beau quand il nage

dans la mer couleur pissou pisse où sur Freud sûrement c'tait rien qu'un Chriss d'adulte la preuve $y$ a jusse les adultes qui ont applaudi

quand j'entends psy, psy, psy, amen je me serre les cuisses pour pas mouiller ma jupe-pantalon (une idée de ma mère libérée)

y s'tapent la tête sur leu murs y sont tous gris tous gris leu maudits murs

pis c'pas une excuse de se dire d'la génération d'la télévision en noir et blanc

passe qu'y étaient trop caves pour voir que noir pis blanc ça allait donner du gris

chat chat viens danser dans l'enchevêtrement plombier de ma cave 


\section{ET VOGUE LA GALĖRE}

la barque qui m'avait cueillie des branches de l'arbre mort est partie à la dérive, la folle et moi aussi folle je la suis

déjà embarquée à fond de cale j'y suis restée de pleines oreilles même lorsqu'elle a décidé de ne plus s'approcher d'aucun débarcadère

alors je ne débarque plus d'ailleurs je n'ai pas fini de visiter la barque s'encombre des mots car Noé voyait grand très grand où est-il que je lui serre la pince et que j'en profite pour lui demander ce qu'il a fait du gouvernail 


\section{CONDOLÉANCES}

Donnez-moi une église à écho de silence où je puisse hurler à la lune

"viens habiter dans mes yeux I'accueil y est vert"

donnez-moi une pelle ou une pioche que je déterre grand-mère "troisième pierre tombale septième rangée"

donnez-moi une montagne où je puisse hurler à la lune aux étoiles et à la Grande Ourse "venez accrocher la Balance à la plus haute branche de l'arbre celui qui dépasse les autres"

papa papa papa ah ah ouin in ouin in in une poussée papa une poussée

je le sais que t'as pas le temps mais les rois $n^{\prime}$ ont pas de couronne dans l'envers du cimetière alors casse ta pipe moi, j'm'envole avec mon chum le vent $y$ a pas un seul fou du balai qui m'arrêtera 


\section{B.E.S.}

les rires gras et bien portants

sautent au plafond

éclaboussent les murs

de postillons

et moi j'attends le mandat-poste

celui de la méfiance efficace

et moi j'attends

une, parmi la file

une et seule

dans les lignes froides du fonctionnarisme sans règle et sans compas

et je ris

d'un rire puant la maladie

celle de la ville

celle qu'on voit sur les murs et le plafond 


\section{ÉCRITURE AUTOMATIQUE AU CARRÉ SAINT-LOUIS}

je ne suis pas un bouton avec le mot PUSH dessus vos signaux de fumée codés en morue à la sournoise passent à côté de moi sans que mon oeil ne chigne ni même kling kling seul le collier du chien fait ting ting je sens l'odeur des caoutchoucs sur l'asphalte, de l'essence qui coule, des grincements de fer contre fer et des splash de fer contre peau je ne fais ni ha ni beurk j'ai décidé qu'il était dangereux de croiser les gros bonhommes qui vont fleur à la main verrues au pied 


\section{UN PLUS UN}

On dit que le jeu de saute-mouton

n'est plus de son âge

alors elle n'a plus qu'a jouer à

sautons-mouton avec les années

Mais comme elle est sans âge

elle a pris de l'avance dans le jeu

elle a joué avec tout le siècle à venir

et elle a sauté une par une

sur chaque année

et sauté tellement fort

qu'elle les a écrasées

toutes sans exception

On dit:

Sorcière! au bûcher!

on t'a vu danser sur nos potirons

regarde la pulpe jaunasse que tu as laissée

alors:

Sorcière, un baiser avant le bûcher!

On t'a vu danser sur le fruit de notre travail

Regarde tes chats se rouler

dans le tapis d'or que tu as laissé

On se trompe:

On te fait rôtir

est-ce bête

au lieu

d'incendier le champ de pâte pulpeuse

d'en faire

un immense gâteau à la citrouille

sans les chandelles pour les années

Je connais:

la nausée qui t'envahissait aux abords de ce champ lorsqu'il t'arrivait d'en avoir la vision

d'en voir les lignes droites et annuelles;

cent potirons en lignes à sens unique

à côté, cent autres potirons

en ligne et ainsi de suite

à perte de vue et de conscience 